\title{
MERCADO DE TRABALHO E A FORMAÇÃO DO ADMINISTRADOR EM UMA IES PÚBLICA EM RECIFE-PE
}

JOB MARKET AND FORMATION OF THE ADMINISTRATOR ON A PUBLIC UNIVERSITY IN RECIFE-PE DOI: http://dx.doi.org/10.12712/rpca.v6i2.121

\author{
Raisa Rio-Branco \\ Universidade Federal de Pernambuco (UFPE) \\ raisario@gmail.com \\ Diogo Henrique Helal \\ Universidade Federal da Paraíba (UFPB) \\ diogo h@yahoo.com
}

\section{Resumo}

Este artigo busca descrever o perfil dos estudantes de administração em Recife-PE, de uma IES pública, com ênfase para a análise da empregabilidade de seus graduandos e de suas expectativas em relação ao mercado de trabalho, depois de formados. Os resultados indicam existir diferenças no perfil dos estudantes que estão ingressando na Universidade em relação aos concluintes. Os alunos iniciantes são em maior número mulheres, com menor renda familiar e em grande parte morenos e pardos. A conclusão do curso aumentou o percentual de alunos empregados ou realizando estágio, além de trazer incremento na renda média mensal. Os alunos concluintes preferem trabalhar em horário flexível, enquanto os iniciantes, em horário fixo. Ambos os grupos esperam ser reconhecidos profissionalmente, após a formatura. Observou-se ainda que os estudantes concluintes dão mais valor à carreira do que os iniciantes. Grande parcela daqueles disse que o tempo ideal para permanecer em uma única empresa seria enquanto o cargo estivesse acrescentando algo a carreira. Por fim, identificou-se que parte dos concluintes se mostrou desiludida com a preparação que o curso proporciona: $24,7 \%$ disse que o curso ofereceu pouca preparação. Tal fato, contudo, não implica negativamente o padrão de vida esperado: ambos os grupos esperam ter salários mais elevados no futuro e um padrão de vida melhor, quando comparado ao dos pais.

Palavras-chave: Mercado de Trabalho. Administração. Formação Profissional.

\begin{abstract}
This article seeks to describe the profile of business students in Recife, from public university, with emphasis on the analysis of the employability of its graduates and their expectations about the job market after graduation. The results indicate no differences in the profile of students who are entering the University in relation to graduate. Beginner students are mainly women, with lower income, and largely brown and black. The completion of the course increased the percentage of students that are employed or performing stage, and bring an increase in the average income. Students graduates prefer to work in flexible jobs, while the beginners, in a fixed schedule. Both groups expect to be recognized professionally after graduation. It was also observed that students graduating give more value to the career, than the beginners. A large portion of those said that the ideal time to stay in one position is while the company would be adding something was his career. Finally, we found that some of the graduates are disillusioned with the preparation obtained from the course provides: $24.7 \%$ said the course offered a little preparation to their career. This fact, however, does not impact negatively in their standard of living expectations: both groups expect to have higher wages in the future and a better standard of living when compared to their parents.
\end{abstract}

Keywords: Job Market. Management. Professional formation. 



\section{Introdução}

As últimas décadas no país têm sido marcadas por importantes alterações na estrutura ocupacional e no mercado de trabalho. Nas décadas de 1970 e 1980 observou-se o esgotamento do modelo fordista de produção e organização do trabalho, impulsionando o surgimento de novas bases institucionais para o desenvolvimento do capitalismo (baseado em modelos flexíveis de produção, com destaque ao capital financeiro).

Sob essa nova égide, as empresas iniciaram um processo de reestruturação, centrado em uma nova revolução tecnológica, de base microeletrônica. Esse momento ficou marcado pela difusão de um novo padrão tecnológico, que possibilitou a passagem da fase de mecanização e automação rígida (característica do modelo fordista/taylorista de produção) para a fase de automação flexível (especialização flexível, para Piore e Sabel (1984), própria do modelo pósfordista.

Mais recentemente, nos anos 1990, o país passou a vivenciar a terceirização de algumas atividades de sua economia. Esse processo está baseado na concentração de esforços, por parte das organizações, em atividades do chamado core business, delegando a terceiros aquelas outras não ligadas ao objetivo principal do negócio. A terceirização e a flexibilização da economia vêm causando fortes impactos no mercado de trabalho em todo o Brasil, que, segundo Pochmann (2001), vive um momento de desestruturação. Para o autor, os novos conhecimentos tecnológicos se associaram às exigências empresariais de contratação de empregados com polivalência multifuncional, maior nível de motivação e habilidades laborais adicionais no exercício do trabalho. A força de trabalho brasileira mudou de uma situação inicial de forte dependência em relação a atividades agropecuárias para uma diversificada estrutura ocupacional urbana.

Ainda é possível registrar que desde a década de 1990, o país tem vivenciado um acelerado processo de informalização e precarização do trabalho, o que gerou uma profunda modificação na qualidade da ocupação desenvolvida no país. Ressalte-se que estas situações se intensificaram nesta década no Brasil, mas não começam nela (CAVALCANTI, 1983; CASTELLS e PORTES, 1989; BARROS, 1997).

Os anos 1990 no Brasil também são caracterizados pelo início da forte expansão da educação superior. 0 crescimento do número de faculdades, cursos e vagas de ensino superior, objetivamente veio suprir o déficit nesta área. Àquela época, as opções para um jovem ingressar em um curso superior se restringiam, na maior parte dos estados brasileiros, às vagas ofertadas por universidades públicas.

Há de se ressaltar, contudo, as críticas sobre esta expansão e o próprio formato desses novos cursos e faculdades, bem como a diferença entre a qualidade do ensino público e privado, que certamente trazem implicações para a análise das relações entre educação e ocupação.

No contexto destas discussões sobre expansão do ensino superior, cabe registrar a enorme e crescente oferta de cursos de graduação em Administração, no Brasil e em boa parte do mundo. Esse fenômeno, de mercantilização do ensino, tem gerado sérios impactos em diversos países. Na Inglaterra, por exemplo, o ambiente neoliberal trouxe uma reforma do ensino universitário, que estimulou a abertura de novas vagas, mudanças na estrutura universitária, dentre outros resultados (PARKER e JARY, 1995). Sobre os Estados Unidos, Pffefer e Fong (2004) mostram que as escolas de Administração estão fracassando no tocante ao seu desempenho como instituições educacionais e de pesquisa, por estarem centradas, em 
grande parte, em interesses instrumentais e de mercado, em detrimentos de objetivos pedagógicos.

No Brasil, ocorreu um fenômeno semelhante de massificação, em função da grande expansão principalmente do ensino privado no nível de graduação. Destaquem-se, ainda, as políticas educacionais de ampliação do acesso às universidades públicas federais, como os programas PROUNI (Programa Universidade para Todos) e REUNI (Programa de Apoio a Planos de Reestruturação e Expansão das Universidades Federais), além de FIES (Fundos de Financiamento ao Estudante do Ensino Superior) e de financiamento para abertura de novas instituições de ensino superior.

Dados do Instituto Nacional de Estudos e Pesquisas Educacionais (Inep) demonstram a evolução do número de cursos e vagas, nomeadamente em faculdades privadas.

Tabela 1 - Evolução do número de cursos de graduação presencial, segundo a organização acadêmica - Brasil 2002 a 2008

\begin{tabular}{l|l|l|l|l|l|l|l|l} 
Ano & Total & $\% \Delta$ & $\begin{array}{l}\text { Universidade } \\
\mathrm{s}\end{array}$ & $\% \Delta$ & $\begin{array}{l}\text { Centros } \\
\text { Universitário } \\
\mathrm{s}\end{array}$ & $\begin{array}{l}\% \Delta \\
\text { Faculdade } \\
\mathrm{s}\end{array}$ & $\% \Delta$ \\
\hline 2002 & 14.399 & - & 8.486 & - & 1.413 & - & 4.500 & - \\
\hline 2003 & 16.453 & 14,3 & 9.396 & 10,7 & 1.618 & 14,5 & 5.439 & 20,9 \\
\hline 2004 & 18.644 & 13,3 & 10.475 & 11,5 & 2.134 & 31,9 & 6.035 & 11,0 \\
\hline 2005 & 20.407 & 9,5 & 10.892 & 4,0 & 2.542 & 19,1 & 6.973 & 15,5 \\
\hline 2006 & 22.101 & 8,3 & 11.552 & 6,1 & 2.717 & 6,9 & 7.832 & 12,3 \\
\hline 2007 & 23.488 & 6,3 & 11.936 & 3,3 & 2.880 & 6,0 & 8.672 & 10,7 \\
\hline 2008 & 24.719 & 5,2 & 12.351 & 3,5 & 3.238 & 12,4 & 9.130 & 5,3
\end{tabular}

Tabela 2 - Evolução do número de cursos de graduação presencial, segundo a categoria administrativa - Brasil -2002 a 2008

\begin{tabular}{|c|c|c|c|c|c|c|c|c|c|c|c|c|}
\hline \multirow{2}{*}{ Ano } & \multirow{2}{*}{ Total } & \multirow{2}{*}{$\% \Delta$} & Pública & Privada & $\% \Delta$ & \multirow[b]{2}{*}{$\% \Delta$} & \multirow[b]{2}{*}{ Estadual } & \multirow[b]{2}{*}{$\% \Delta$} & \multirow[b]{2}{*}{ Municipal } & \multirow[b]{2}{*}{$\% \Delta$} & & \\
\hline & & & Total & $\% \Delta$ & Federal & & & & & & & \\
\hline 2002 & 1.773 .087 & - & 295.354 & - & 124.196 & - & 132.270 & - & 36.866 & - & 1.477 .733 & - \\
\hline 2003 & 2.002 .733 & 13,0 & 281.213 & $-4,8$ & 121.455 & $-2,2$ & 111.863 & $\begin{array}{c}- \\
15,4 \\
\end{array}$ & 47.895 & 23,2 & 1.721 .520 & 16,5 \\
\hline 2004 & 2.320 .421 & 15,9 & 308.492 & 9,7 & 123.959 & 2,1 & 131.675 & 17,7 & 52.858 & 10,4 & 2.011 .929 & 16,9 \\
\hline 2005 & 2.435 .987 & 5,0 & 313.368 & 1,6 & 127.334 & 2,7 & 128.948 & $-2,1$ & 57.086 & 8,0 & 2.122 .619 & 5,5 \\
\hline 2006 & 2.629 .598 & 7,9 & 331.105 & 5,7 & 144.445 & 13,4 & 125.871 & $-2,4$ & 60.789 & 6,5 & 2.298 .493 & 8,3 \\
\hline 2007 & 2.823 .942 & 7,4 & 329.260 & $-0,6$ & 155.040 & 7,3 & 113.731 & $-9,6$ & 60.489 & $-0,5$ & 2.494 .682 & 8,5 \\
\hline 2008 & 2.985 .137 & 6,7 & 344.038 & 4,5 & 169.502 & 9,3 & 116.285 & 2,2 & 58.251 & $-3,7$ & 2.641 .099 & 5,9 \\
\hline
\end{tabular}

Fonte: MEC/INPE/DEED

É crescente o número de pessoas beneficiadas pelos programas e políticas públicas federais de ensino superior: pelo PROUNI em Pernambuco, 1.733 pessoas foram beneficiadas, destas 858 na capital (MEC, 2005). Somente no primeiro semestre de 2010, 2.560 foram beneficiadas no Estado, no mesmo programa, sendo 1.168 na capital (MEC, 2010). Já o programa FIES desde o seu início, em 1999, beneficiou 562 mil estudantes, no país. Atualmente, são beneficiados 486 mil estudantes (contratos ativos; dados do Fundo Nacional de 
Desenvolvimento da Educação).

Convém destacar que a combinação entre uma grande procura de vagas e o custo relativamente baixo de implantação de um curso de graduação em Administração torna esse curso atraente para a iniciativa privada. Segundo dados do INEP/MEC, em 2008, existiam 1.809 cursos de graduação em Administração no Brasil, oferecendo 388.804 vagas (13,02\% do total). Trata-se do curso com maior oferta de vagas no Brasil. 0 curso de graduação que ofereceu mais vagas, logo a seguir, em 2008, foi o de Direito, com 240.077 vagas. Os dados do MEC indicam também que em 2008 eram 714.408 alunos matriculados em Administração no país.

Assim, é interesse desta pesquisa descrever o perfil dos estudantes de administração em Recife-PE, de uma IES pública, com ênfase para a análise da empregabilidade de seus graduandos e de suas expectativas em relação ao mercado de trabalho, depois de formados.

\section{Histórico do ensino em Administração no Brasil}

A formação profissional em Administração no Brasil é relativamente recente. Apesar de se ter registro dos primeiros cursos no país já no início do século XX, sem a devida regulamentação (OLIVEIRA e SAUERBRONN, 2007), é a partir da década de 1940 que se inicia uma proposta de formação de administradores no país:

A partir do Dasp, foi criada em 1944 a Fundação Getulio Vargas (FGV) visando à formação de pessoal para a administração pública e privada. Em 1952, tem início o curso de graduação em administração pública da Escola Brasileira de Administração Pública (Ebap), Logo em seguida, 1954, a Escola de Administração de Empresas de São Paulo (Eaesp) iniciou a graduação em administração de empresas. (OLIVEIRA e SAUERBRONN, 2007,p.152)

Bertero (2006, p.03) lembra que "o crescimento do ensino de administração coincide com o aumento da importância dos Estados Unidos no século XX, quando se consolidam como superpotência".

Nesse sentido, a formação em administração no país se associou a um contexto de modernização. Oliveira (2006) afirma que as origens do curso de administração estão associadas à necessidade de modernização do Estado e de desenvolvimento econômico do país.

Bertero (2006), contudo, lembra que a expansão do curso de Administração no Brasil ocorreu de modo massificado, diferentemente do que aconteceu nos Estados Unidos e na Europa.

A massificação de cursos de administração não é típica de sistemas educacionais nem se coaduna com a natureza da profissão de administrador. Pode ser afirmado que em qualquer sociedade o número de administradores é sempre relativamente reduzido, pela própria natureza do trabalho administrativo e pela estrutura das diversas organizações que empregam administradores. Em uma empresa, organizações sem fins lucrativos, hospitais ou órgãos da administração pública, os organogramas indicam ser reduzido o número de administradores e não haver muito como aumentá-lo. Ou, em outros termos, sempre haverá um número elevado de administrados para relativamente poucos administradores. Isso equivale a dizer que a profissão de administrador é socialmente oligárquica. Em nenhuma sociedade será possível empregar massas de administradores como as que se graduam em 
nossos programas de graduação em todo o país. (BERTERO, 2006, p.20).

Ainda sobre o processo de mercantilização do ensino superior, Oliveira e Sauerbronn (2007, p.156) explicam:

Porém, um dos principais desafios à educação superior é a necessidade de ampliar o acesso a ela e, ao mesmo tempo, controlar seu processo de "mercantilização". A noção de universidade mercantil se tornou ainda mais forte no Brasil em função do quadro de demanda reprimida, no qual as instituições particulares de ensino superior surgem como mecanismo de democratização do acesso ao ensino superior, ampliando significativamente a oferta de produtos educacionais. Esta característica se torna mais marcante nos dias atuais se considerarmos o crescimento do Prouni e as metas do governo federal.

Bertero (2006) justifica que a intensa mercantilização do curso de administração se dá pela elevada demanda, baixo custo e reduzidos investimentos de que o curso necessita. Sendo, assim, "empresarialmente um produto interessante" (BERTERO, 2006, p.22)

É importante frisar que a Lei de Diretrizes e Bases (LDB), Lei 9.394, de 1996 (BRASIL, 1996) propiciou, também, um crescimento de Instituições de Ensino Superior (IES). Neste contexto houve natural aumento do número de IES e de competitividade entre elas.

Abdullah apud Mainardes e Domingues (2010, p.210) simplifica exatamente como se encontra a atividade de ensino superior hoje no Brasil:

(...) o ensino superior parece estar se dirigindo a uma competição comercial imposta por forças econômicas, resultado do desenvolvimento da comercialização da educação. As IES da atualidade estão tendo que se interessar não só pelo que a sociedade solicita, em termos de competência dos diplomados, mas também pelo que os estudantes sentem sobre a experiência educacional que têm, vão ter ou tiveram.

O maior problema, no entanto, é a questão da qualidade do ensino que é ofertada pelas IES. Para Walter, Tontini e Domingues (2005, p. 1), "o mercado educacional aproxima-se cada vez mais de um mercado onde a qualidade dos serviços e a satisfação dos clientes são fundamentais para sobrevivência das IES".

Motta (1983) considera que o problema da qualidade do ensino em administração não é contingencial, mas estrutural, em face da ausência de identidade e prestígio do curso, na sua implantação no país. 0 autor (1983) já discutia, àquela época, o problema da massificação do ensino de Administração e o conseqüente contingente de formandos colocados no mercado de trabalho, questionando "a razão desse número crescente de formandos e de administradores profissionais em geral” (MOTTA, 1983, p.54).

\section{Formação profissional do administrador e mercado detrabalho}

Além da questão da desconfiança sobre a real qualidade dos cursos de graduação em administração, há ainda outros agravantes que afetam a formação de bons profissionais na área. Bertero (2006) afirma que grande parte dos estudantes de administração certamente não contempla a carreira de administrador com o objetivo de mobilidade social.

(...) podemos inferir que a maioria das pessoas matriculadas em cursos de graduação de administração no país tem pouca consciência do que seja uma 
carreira plena de administrador. Suas origens sociais e seu imaginário nem mesmo incluem tais itinerários e suas aspirações não as levam a buscar carreiras em grandes empresas nem embarcar em um universo de organizações multinacionais. Na verdade, aspiram a uma melhoria relativamente modesta de suas condições de trabalho, que lhes permita uma reduzida mobilidade na esfera socioeconômica em que se encontram (BERTERO, 2006, p.38).

Assim, aspectos ligados à qualidade do ensino, à própria postura (descompromissada) de parte do alunado do curso geram importantes impactos na identidade e status profissional do administrador, na sociedade. Por exemplo, Motta (1983) considera que há ausência de identidade e prestígio do curso de Administração no país. Somam-se a isso o baixo status profissional da carreira de administração, a fraqueza de atuação dos conselhos de classe (CFA e CRA's), bem como a presença de outros profissionais em atividades de gestão nas organizações.

A profissão de administrador não é exercida necessariamente por pessoas que tenham sido escolarizadas em administração. Entre nós, engenheiros ocupam com frequência posições administrativas, especialmente no setor empresarial, tanto privado como estatal. 0 fenômeno não é apenas brasileiro, mas pode ser encontrado em diversos países. (BERTERO, 2006, p.39-40).

Além da engenharia, outras escolarizações fornecem quadros para a profissão de administrador. Economistas, advogados, cientistas sociais, pedagogos e psicólogos podem ser encontrados, com freqüência, ocupando posições administrativas. Aqui há uma tendência a que as diferentes profissões, quando se convertem na administração, optem e se fixem em algumas áreas funcionais (BERTERO, 2006, p.40-41).

É interessante observar a predominância de engenheiros que ocupam funções de gestores e as possíveis razões para esse fato, segundo Bertero (2006):

(...) a profissão de engenheiro continua a ser importante fonte de gestores. Isso talvez se deva ao fato de que cursos de engenharia não se massificaram como os de administração e seus formandos, consequentemente, acumularam um capital social e intelectual de que os bacharéis em administração carecem. (BERTERO, 2006, p.23).

Todo esse contexto faz com que, na opinião de alguns autores, haja uma subutilização dos administradores no mercado de trabalho: "Os empregos de administração são, na verdade, empregos para executores e poucos para executivos” (BERTERO, 2006, p.124).

Sobre esse assunto, Mainardes e Domingues (2010) destacam:

(...) a graduação em administração atual não tem formado os líderes que o mercado de trabalho procura e muitos dos bacharéis continuam atuando nas mesmas funções de antes da graduação. 0 caminho utilizado para o crescimento profissional tem sido a realização de uma pós-graduação lato sensu. (MAINARDES, E.; DOMINGUES, M., 2010, p.216).

Ainda de acordo com os autores (2010):

(...) esperava-se que formandos em administração já estivessem exercendo 
funções de liderança por terem realizado praticamente todo o curso de administração, mas o que se observou é que a graduação não garante o crescimento profissional dos 'indivíduos' (MAINARDES, E.; DOMINGUES, M., 2010, p.221).

Esse debate indica um desequilíbrio entre oferta de postos de trabalho para o administrador, e demanda por parte dos trabalhadores. Tem-se, no caso do administrador um desequilíbrio: o número de formandos é cada vez maior; formandos de outros cursos disputam o mercado de trabalho com administradores; o número de vagas para gestores não cresce no mesmo ritmo do crescimento da oferta destes. Tal contexto faz com que boa parcela dos formandos em administração: (1) esteja desempregada; (2) esteja empregada em ocupações mais precárias e em atividades pouco ligadas à sua formação; (3) receba remuneração abaixo do mercado, em comparação com outras ligadas a ocupações de nível superior.

\section{Procedimentos metodológicos}

Este artigo descreve e analisa o perfil do profissional do administrador por meio de percepções de alunos do referido curso, em uma IES pública. Trata-se de uma pesquisa descritiva a partir de dados primários, que foram analisados a partir da perspectiva quantitativa, em uma análise univariada. Nesta, buscou-se aferir o percentual de respondentes nas opções de resposta e realizar posterior análise à luz do referencial teórico escolhido.

Os dados primários foram obtidos por meio da aplicação de questionários com alunos do curso de Administração da IES estudada. 0 instrumento de coleta de dados foi elaborado em três partes: perfil, trabalho atual e preferências, carreira e expectativas. Foi realizado um préteste do instrumento com 10 alunos, sendo 5 iniciantes e 5 concluintes. Em seguida, foram realizados ajustes no questionário.

A abordagem quantitativa foi utilizada com o propósito de melhor identificar o perfil dos alunos e suas expectativas em relação ao mercado de trabalho. Intenciona-se também a generalização dos resultados no que diz respeito ao perfil demográfico dessesalunos.

No total de alunos, optou-se por entrevistar alunos iniciantes e concluintes. Para tanto, foram considerados como iniciantes aqueles alunos que freqüentavam disciplinas nos $1^{\circ}$ e $2^{\circ}$ períodos e como concluintes aqueles que freqüentavam disciplinas nos $8^{\circ}$ e $9^{o}$ períodos. Os questionários foram aplicados no período de 28 de outubro a 12 de novembro de 2010.

Foram entrevistados os alunos presentes nas disciplinas de Ética e Filosofia para o Administrador (turno da noite), Tecnologia da Informação (turnos manhã e noite) e Fundamentos de Sociologia (turno da noite), como iniciantes, e das disciplinas Administração da Qualidade e Estratégia Empresarial (turno da noite), como concluintes. Ressalte-se que o referido curso nos períodos finais é ofertado apenas à noite.

\section{Apresentação e Análise dos Resultados}

Esta seção apresenta e analisa os dados obtidos por meio da aplicação dos questionários. Para um melhor entendimento, foram agrupados nas seguintes categorias: 1- Descrição do Perfil; 2- Trabalho; 3- Preferências, Carreira e Expectativas.

a) Descrição do Perfil 
Tabela 3 - Cor da pele

\begin{tabular}{l|l|l|l} 
& Iniciantes (\%) & Concluintes (\%) & $\begin{array}{l}\text { Total de alunos (iniciantes + } \\
\text { concluintes) (\%) }\end{array}$ \\
\hline Branco & $44,4 \%$ & $55,7 \%$ & $49,3 \%$ \\
\hline Negro & $5,1 \%$ & $3,4 \%$ & $4,4 \%$ \\
\hline Moreno & $28,2 \%$ & $22,7 \%$ & $25,9 \%$ \\
\hline Pardo & $17,1 \%$ & $13,6 \%$ & $15,6 \%$ \\
\hline Amarelo & $5,1 \%$ & $4,5 \%$ & $4,9 \%$ \\
\hline $\begin{array}{l}\text { Total } \\
\text { Fonte: dados da pesquisa }\end{array}$ & 120 alunos & 89 alunos & 219 alunos
\end{tabular}

No que se refere à cor de pele dos entrevistados, 49,3\% afirmaram ser brancos, 4,4\%, negros, $25,9 \%$, morenos, $15,6 \%$ pardos e 4,9\%, amarelos. Contudo, ao se comparar os alunos iniciantes e concluintes, percebe-se diferença no perfil. Por exemplo, 36,3\% dos concluintes são morenos e pardos. Por sua vez, entre os iniciantes esse percentual é de $45,3 \%$.

Tabela 4 - Sexo

\begin{tabular}{c|l|l|l} 
& Iniciantes (\%) & Concluintes (\%) & $\begin{array}{l}\text { Total de alunos } \\
\text { (iniciantes + concluintes) (\%) }\end{array}$ \\
\hline Masculino & $49,2 \%$ & $60,7 \%$ & $54,1 \%$ \\
\hline Feminino & $50,8 \%$ & $39,3 \%$ & $45,9 \%$ \\
\hline Total & 120 alunos & 89 alunos & 219 alunos \\
Fonte: dados da pesquisa & &
\end{tabular}

Fonte: dados da pesquisa

Ao se observar o sexo dos entrevistados, nota-se que 39,3\% dos concluintes são do sexo feminino. Tal percentual é de 50,8\% nos ingressantes.

Tabela 5 - Renda Familiar

\begin{tabular}{l|l|l|l} 
& $\begin{array}{l}\text { Iniciantes } \\
(\%)\end{array}$ & Concluintes (\%) & $\begin{array}{l}\text { Total de alunos } \\
\text { (iniciantes + concluintes) (\%) }\end{array}$ \\
\hline Até 1 SM (salário mínimo) & $0,9 \%$ & $0 \%$ & $0,5 \%$ \\
\hline Mais de 1 SM até 2 SM & $5,3 \%$ & $2,3 \%$ & $4 \%$ \\
\hline Mais de 2 SM até 3 SM & $12,4 \%$ & $3,4 \%$ & $8,5 \%$ \\
\hline Mais de 3 SM até 4 SM & $5,3 \%$ & $3,4 \%$ & $4,5 \%$ \\
\hline Mais de 4 SM até 5 SM & $10,6 \%$ & $4,5 \%$ & $8 \%$ \\
\hline Mais de 5 SM até 7 SM & $13,3 \%$ & $8 \%$ & $10,9 \%$ \\
\hline Mais de 7 SM até 10 SM & $15,9 \%$ & $28,4 \%$ & $21,4 \%$ \\
\hline Mais de 10 SM até 20 SM & $26,5 \%$ & $31,8 \%$ & $28,9 \%$ \\
\hline $\begin{array}{c}\text { Acima de 20 SM } \\
\text { Fonte: dados da pesquisa }\end{array}$ & $9,7 \%$ & $18,3 \%$ & $13,4 \%$
\end{tabular}

No que diz respeito à renda familiar, há diferença entre os ingressantes e concluintes. Enquanto 50\% dos alunos concluintes têm renda familiar acima de 10 salários mínimos (SM), esse percentual é de apenas 36,2\% nos alunos ingressantes.

A partir desses dados, pode-se perceber que existem diferenças no perfil dos estudantes de 
Administração que estão ingressando na Universidade em relação aos que estão se graduando. Os alunos iniciantes são em maior número mulheres, com menor renda e em grande parte morenos e pardos.

A diferença no que diz respeito à cor e à renda dos estudantes entrevistados pode ser resultado da política de ação afirmativa que a IES tem promovido em seus vestibulares. Desde o ano de 2007, os alunos que estudaram o ensino médio em escola pública têm um acréscimo de $10 \%$ no argumento final de classificação do vestibular.

Apesar da efetividade da política de universalização de ensino superior no país, algumas IES públicas tem percebido que a elite tem acesso privilegiado ao ensino superior. Trata-se de claro movimento de reprodução social, via educação (BOURDIEU, 1987). As políticas de ação afirmativa passam a ser necessárias, como importantes instrumentos de combate à desigualdade social (FERNANDES e HELAL, 2010).

b) Trabalho

Tabela 6 - Realiza atividade profissional como trabalhador, estagiário ou bolsista e renda média mensal

\begin{tabular}{l|c|c} 
& Iniciantes (\%) & Concluintes (\%) \\
\hline Sim & 40,8 & 76,4 \\
\hline $\begin{array}{c}\text { Renda Média Mensal (R\$) } \\
\text { Fonte: dados da pesquisa }\end{array}$ & $\mathrm{R} \$ 892,65$ & $\mathrm{R} \$ 1.680,80$
\end{tabular}

Dos alunos iniciantes, $40,8 \%$ trabalham, fazem estágio ou são bolsistas; tal percentual é de $76,4 \%$ no que se refere aos concluintes. 0 ramo de atuação dos estudantes ingressantes se concentra nas atividades de comércio e serviço público, com 64,6\%. Entre os concluintes, 14, $7 \%$ estão no setor industrial, $10,3 \%$ no comércio, $35,3 \%$ no serviço público e $10,3 \%$ em instituições financeiras, bancos e agências de crédito.

No que diz respeito à renda mensal, a média para os estudantes dos primeiros períodos se encontra em $R \$ 892,65$, enquanto que esse valor quase dobra para os alunos dos últimos períodos: $\mathrm{R} \$ 1.680,80$.

Como era de se esperar, os investimentos em capital humano (SCHULTZ, 1961) trouxeram retornos econômicos aos estudantes, em particular no que se refere a obtenção de postos de trabalho e melhoria salarial. Tais achados corroboram os encontrados por Helal, Neves e Fernandes (2007), acerca dos impactos do capital humano na empregabilidade dos indivíduos.

Tabela 7 - Procurou emprego nos últimos 30 dias

\begin{tabular}{l|l|l} 
& Iniciantes (\%) & Concluintes (\%) \\
\hline Sim & 28 & 27,3 \\
\hline Não & 72 & 72,7
\end{tabular}

Fonte: dados da pesquisa

Quando perguntados sobre se haviam procurado trabalho nos últimos 30 dias, o percentual foi equivalente para os dois grupos: $28 \%$ iniciantes, $27,3 \%$ concluintes. 
Tabela 8 - Consulta a parentes, amigos ou colega para conseguir trabalho/estágio

\begin{tabular}{c|l|l} 
& Iniciantes (\%) & Concluintes (\%) \\
\hline Sim & 58 & 48,2 \\
\hline Não & 42 & 51,8 \\
Fonte: dados da pesquisa
\end{tabular}

A rede de relacionamentos tem importância significativa para os dois grupos no que diz respeito ao acesso ao emprego. Para os alunos iniciantes, 58\% consultaram sua rede para conseguir um posto de trabalho, enquanto que esse valor foi de $48,2 \%$, entre os concluintes.

Pode-se inferir que com o passar dos anos na faculdade e o conseqüente acúmulo de conhecimento, os estudantes têm significativa melhora salarial e consultam menos a rede de relacionamento para conseguirem emprego. Imagina-se que os alunos concluintes, por terem já alguma experiência em empregos e/ou estágios em Administração, não necessitem, na mesma medida que os iniciantes, da rede de relacionamentos para obtenção de oportunidades no mercado de trabalho.

É sabido também, e os dados desta pesquisa apontam nesta direção, que apenas os investimentos em capital humano não asseguram melhores postos de trabalho. Cada vez mais, com a massificação do ensino superior, a posse de outros tipos de capital, como o cultural e social, permite e por vezes garante melhores oportunidades no mercado de trabalho. Autores como Bourdieu (1980) e Granovetter $(1973 ; 1995)$ entendem que as redes de relacionamento são capital social e sua posse permite acesso a melhores ocupações. Granovetter (1973), em particular, se refere ao poder de influência indireta dos relacionamentos, inclusive aqueles fora do círculo imediato da família e dos amigos próximos (strong ties). Para o autor (GRANOVETTER, 1995, p.52-54;148), tais relacionamentos, baseados em laços fracos (indiretos) são importantes pois conectam os indivíduos a uma maior gama de informações e conhecimentos relativos a vagas e oportunidades de emprego.

c) Preferências, carreira e expectativas

Tabela 9 - Preferência por horário de trabalho

\begin{tabular}{l|l|l} 
& Iniciantes (\%) & Concluintes (\%) \\
\hline Horário fixo & 62,2 & 38,2 \\
\hline Horário flexível & 34,5 & 60,7 \\
\hline $\begin{array}{c}\text { Outras opções } \\
\text { Fonte: dados da pesquisa }\end{array}$ & 3,4 & 1,1
\end{tabular}

A preferência pelo horário de trabalho entre os dois grupos é diversa: $62,2 \%$ dos iniciantes afirmaram preferir um horário fixo em detrimento de um horário flexível, enquanto que esse percentual foi de $38,2 \%$ para os alunos concluintes.

Tabela 10 - Preferência por tipo de cargo

\begin{tabular}{l|l|l} 
& Iniciantes (\%) & Concluintes (\%) \\
\hline Cargo mais alto, maiores remuneração e responsabilidade & 87,4 & 89.9 \\
\hline $\begin{array}{l}\text { Cargo mais modesto, menores remuneração e e } \\
\text { responsabilidade }\end{array}$ & 10,1 & 12,4 \\
\hline
\end{tabular}


Outras opções

Fonte: dados da pesquisa

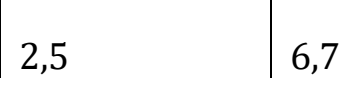

Os estudantes de administração têm preferência por um cargo mais alto, com maiores remuneração e responsabilidades: os percentuais observados entre os iniciantes e concluintes foram, respectivamente, $87,4 \%$ e $80,9 \%$.

Tabela 11 - Preferência por local de trabalho

\begin{tabular}{l|l|l} 
& Iniciantes (\%) & Concluintes (\%) \\
\hline Casa & 25,4 & 36 \\
\hline Empresa & 71,2 & 57,3 \\
\hline $\begin{array}{r}\text { Outras opções } \\
\text { Fonte: dados da pesquisa }\end{array}$ & 6,7
\end{tabular}

A proposta de trabalhar em casa, caso a empresa permitisse tal possibilidade, foi minoria nos dois grupos: $25,4 \%$ para os iniciantes e $36 \%$ para os concluintes.

Pode-se perceber, assim, que os estudantes concluintes e iniciantes diferem na preferência de horário de trabalho: os primeiros preferem horário mais flexível, os últimos preferem horário fixo. Possivelmente, essa diferença decorra do fato de que os concluintes já estão no mercado de trabalho há mais tempo e sabem do benefício tanto pessoal quanto profissional que esse tipo de jornada (flexível) proporciona. Estes resultados se aproximam aos observados por Mainardes e Domingues (2010).

Tabela 12 - Vontade de ter negócio próprio

\begin{tabular}{l|l|l} 
& Iniciantes (\%) & Concluintes (\%) \\
\hline Sim & 74,8 & 64 \\
\hline Já tem negócio próprio & 4,2 & 11,2 \\
\hline $\begin{array}{l}\text { Não } \\
\text { Fonte: dados da pesquisa }\end{array}$ & 21 & 24,7
\end{tabular}

A maioria dos estudantes de administração, nos dois grupos, afirmou ter vontade de abrir negócio próprio: 74,8\% ingressantes e 64,0\% concluintes.

Tabela 13 - 0 que pretende fazer quando se formar:

\begin{tabular}{l|l|l} 
& Iniciantes (\%) & Concluintes (\%) \\
\hline Trabalhar em negócio próprio ou de família & 31,6 & 20,7 \\
\hline Trabalhar com profissional liberal & 0,9 & 5,7 \\
\hline Carreira pública & 32,5 & 41,4 \\
\hline Trabalhar em uma grande empresa & 35 & 32,2
\end{tabular}

Fonte: dados da pesquisa

A pretensão dos estudantes sobre o que fazer quando se formarem se dividiu entre os dois grupos. No grupo dos ingressantes, 31,6\% afirmaram que pretendem trabalhar em negócio próprio ou de família, 0,9\% trabalhar como profissional liberal, 32,5\% fazer concurso para seguir carreira pública e 35\% procurar emprego em uma grande empresa. No grupo dos concluintes, $20,7 \%$ afirmaram que pretendem trabalhar em negócio próprio ou de família, 5,7\% trabalhar como profissional liberal, 41,4\% fazer concurso para seguir carreira pública e $32,2 \%$ procurar emprego em uma grande empresa. 
É interessante observar o elevado percentual (e o crescimento entre iniciantes e concluintes) de alunos que pretendem ser servidores públicos e, paralelamente, a diminuta (e declinante) parcela de estudantes que pretendem trabalhar em negócio próprio ou de família. Considerase que tal resultado traz em si um paradoxo: apesar de o curso de administração estar fortemente influenciado pelo ideário liberal (PAES DE PAULA e RODRIGUES, 2006), a escolha pelo empreendedorismo é pequena e declina a medida que os alunos avançam no curso. Estudos mostram que os estudantes de Administração se apropriam da acepção neoliberal de empregabilidade, na qual se consideram responsáveis pela sua inserção no mercado de trabalho (HELAL e ROCHA, 2011). Os resultados desta pesquisa, contudo, indicam que quase metade dos concluintes buscam ingressar no serviço público.

As expectativas salariais, em média, sobre quanto estarão ganhando em 2015, é de R\$ 5.300,91 para os iniciantes e $\mathrm{R} \$ 12.052,94$ para concluintes.

Tabela 14 - 0 que irá acontecer no seu emprego após sua formatura:

\begin{tabular}{l|l|l} 
& Iniciantes (\%) & Concluintes (\%) \\
\hline $\begin{array}{l}\text { Poderá falar sobre as próprias idéias para } \\
\text { melhorar os processos da empresa }\end{array}$ & 33,3 & 42 \\
\hline $\begin{array}{l}\text { Vai ficar alguns meses sem uma tarefa } \\
\text { importante, apenas entendendo o } \\
\text { funcionamento do setor em que trabalha }\end{array}$ & 21,4 & 23,5 \\
$\begin{array}{l}\text { Vai ser exigido ao máximo e ter que provar, logo } \\
\text { na 1atarefa que merece olugar }\end{array}$ & 32,5 & 22,2 \\
\hline Terá alguém próximo que irá aconselhá-lo & 12,8 & 12,3
\end{tabular}

Fonte: dados da pesquisa

Quando questionados sobre o que iria acontecer nos seus respectivos empregos após a formatura em Administração, 33,3\% dos ingressantes afirmaram que iriam poder falar sobre suas idéias para melhorar os processos da empresa e 32,5\% que iriam ser mais exigidos e teriam que provar que mereciam o posto de trabalho. Dos alunos concluintes, $42 \%$ afirmaram que iriam poder falar sobre suas ideias para melhorar os processos da empresa e 22,2\% que iriam ser mais exigidos e teriam que provar que mereciam o posto de trabalho. Pode-se perceber, assim, que quando se formarem, os estudantes esperam se reconhecidos profissionalmente.

Tabela 15 - Empresa ideal:

\begin{tabular}{l|l|l} 
& Iniciantes (\%) & Concluintes (\%) \\
\hline Tem um plano de carreira e paga bem aos funcionários & 54,8 & 59,6 \\
\hline Tem um bom ambiente de trabalho & 33,9 & 37,1 \\
\hline Oferece a melhor proposta do momento & 3,5 & - \\
\hline É multinacional & 7,8 & 3,4
\end{tabular}

Fonte: dados da pesquisa

Para os estudantes iniciantes, $54,8 \%$ disseram que a empresa ideal seria aquela que oferecesse um plano de carreira e pagasse bem ao funcionário e 33,9\% disseram que a empresa ideal seria aquela que oferecesse um bom ambiente de trabalho. Esses percentuais para os concluintes foram de $59,6 \%$ e $37,1 \%$, respectivamente. 
Tabela 16 - Tempo de permanência em uma única empresa:

\begin{tabular}{l|l|l} 
& Iniciantes (\%) & Concluintes (\%) \\
\hline $\begin{array}{l}\text { Construir a carreira na empresa até chegar ao cargo } \\
\text { mais alto }\end{array}$ & 38,3 & 20,7 \\
\hline $\begin{array}{l}\text { Ficar no máximo } 10 \text { anos e partir para outras } \\
\text { experiências }\end{array}$ & 1,7 & 4,6 \\
\hline $\begin{array}{l}\text { Ficar até quando o cargo estiver acrescentando algo à } \\
\text { carreira }\end{array}$ & 54,2 & 70,1 \\
\hline $\begin{array}{l}\text { Procurar mudar constantemente, atrás de propostas } \\
\text { mais interessantes }\end{array}$ & 5,8 & 4,6
\end{tabular}

Fonte: dados da pesquisa

Quanto ao tempo de permanência em uma única empresa, os iniciantes consideraram que o ideal seria construir a carreira na empresa até chegar ao cargo mais alto (38,3\%) e 54,2\% consideraram que o ideal seria permanecer no cargo enquanto estivesse acrescentando algo a carreira. Já para os concluintes, esses percentuais foram de 20,7\% e 70,1\%, respectivamente.

Tabela 17 - Quão preparado o curso vai deixar:

\begin{tabular}{l|l|l} 
& Iniciantes (\%) & Concluintes (\%) \\
\hline Muito bem preparado & 31,7 & 11,2 \\
\hline Bem preparado & 62,5 & 62,9 \\
\hline $\begin{array}{c}\text { Pouco preparado } \\
\text { Fonte: dados da pesquisa }\end{array}$ & 5,8 & 24,7
\end{tabular}

Quando perguntados sobre quão preparados o curso de Administração os iria deixar, no grupo dos iniciantes $31,7 \%$ disseram que muito bem preparado, 62,5\% bem preparado, 5,8\% pouco preparado. No grupo dos concluintes, $11,2 \%$ disseram que muito bem preparado, $62,9 \%$ bem preparado, $24,7 \%$ pouco preparado.

Tabela 18 - Padrão de vida, quando tiver a idade dos seus pais:

\begin{tabular}{l|l|l} 
& Iniciantes (\%) & Concluintes (\%) \\
\hline Melhor & 85 & 82 \\
\hline Igual & 14,2 & 15,7 \\
\hline Pior & 0,8 & 2,2
\end{tabular}

Fonte: dados da pesquisa

Os estudantes dos dois grupos possuem boas expectativas de melhora no padrão de vida quando comparado ao dos pais: $85 \%$ dos ingressantes disseram que terão uma melhora e $14,2 \%$ disseram que terão o padrão de vida igual ao dos pais. Esses percentuais para os concluintes foram de $82 \%$ e $15,7 \%$, respectivamente.

Pode-se perceber que os estudantes concluintes dão mais valor à carreira do que os iniciantes: a grande maioria daqueles disse que o tempo ideal para permanecer em uma única empresa seria enquanto o cargo estivesse acrescentando algo a carreira. Um dado interessante observado refere-se ao fato de que parte dos concluintes se mostrou desiludida com a preparação que o curso proporciona: uma parcela significativa $24,7 \%$ disse que ficaria pouco preparada após a graduação. Porém, tal fato não implicou negativamente o padrão de vida esperado. Tanto nesse grupo, quanto no grupo dos iniciantes há grandes expectativas de melhora no padrão de vida quando comparado ao dos pais. 
A opinião de Bertero (2006) de que os estudantes de administração não contemplam a carreira de administrador com o objetivo de chegar a seu topo e de que suas aspirações não os levam a buscar carreiras em grandes empresas nem embarcar em um universo de organizações multinacionais não se confirmou para os estudantes entrevistados. Mais de 80\% dos alunos, tanto no grupo dos iniciantes, quanto no de concluintes, responderam que preferem cargos mais altos, com maiores remuneração e responsabilidade. Mais de 30\% nos dois grupos afirmaram que quando se formarem, pretendem trabalhar em uma grande empresa. Outro dado de contradiz Bertero (2006) é sobre o tempo que os estudantes afirmaram que seria o ideal para permanecer em uma única empresa. "Ficar até quando o cargo estiver acrescentando algo à carreira" foi a resposta majoritária nos dois grupos (54,2\% iniciantes e 70,1\% concluintes). Quando perguntado sobre qual seria a empresa ideal para se trabalhar, mais de $50 \%$ dos alunos disseram que seria aquela que tem um plano de carreira e boa perspectiva de remuneração.

De outra parte, tem havido uma subutilização dos administradores no mercado de trabalho: "Os empregos de administração são, na verdade, empregos para executores e poucos para executivos” (BERTERO, 2006, p.124).

Mainardes e Domingues (2010) destacam:

(...) a graduação em administração atual não tem formado os líderes que o mercado de trabalho procura e muitos dos bacharéis continuam atuando nas mesmas funções de antes da graduação. 0 caminho utilizado para o crescimento profissional tem sido a realização de uma pós-graduação lato sensu. (MAINARDES, E.; DOMINGUES, M., 2010, p.216).

Ainda de acordo com os autores (2010):

(...) esperava-se que formandos em administração já estivessem exercendo funções de liderança por terem realizado praticamente todo o curso de administração, mas o que se observou é que a graduação não garante o crescimento profissional dos 'indivíduos' (MAINARDES, E.; DOMINGUES, M., 2010, p.221).

Apesar de essas constatações não terem sido respondidas diretamente por meio dos resultados da pesquisa, o que se pôde observar é que os estudantes esperam se reconhecidos profissionalmente. Nessa expectativa se inclui mais do que operações de executores, mas realizar funções da natureza da profissão de administrador, como planejamento, liderança e controle.

\section{Considerações finais}

A expansão do ensino superior no Brasil, e em particular, dos cursos de Administração, tem tornado a inserção profissional do graduando um desafio. Nesta senda, este artigo buscou descrever o perfil dos estudantes de administração em Recife-PE, de uma IES pública, com ênfase para a análise da empregabilidade de seus graduandos e de suas expectativas em relação ao mercado de trabalho, depois de formados.

Os resultados indicam existir diferenças no perfil dos estudantes que estão ingressando na Universidade em relação aos concluintes. Os alunos iniciantes são em maior número mulheres, com menor renda familiar e em grande parte morenos e pardos. Tal alteração se deu em função da política de cotas sociais implementada na Universidade, desde 2007, 
quando do vestibular.

O curso trouxe mudanças significativas aos alunos, no que se refere a inserção no mercado de trabalho e retorno salarial. Dos alunos iniciantes, $40,8 \%$ trabalham, fazem estágio ou são bolsistas; tal percentual é de 76,4\% entre os concluintes. No que diz respeito à renda mensal, a média para os estudantes dos primeiros períodos se encontra em $\mathrm{R} \$ 892,65$, enquanto que esse valor quase dobra para os alunos dos últimos períodos: $\mathrm{R} \$ 1.680,80$.

A rede de relacionamentos tem importância significativa para os dois grupos no que diz respeito ao acesso ao emprego. Para os alunos iniciantes, $58 \%$ consultaram sua rede para conseguir um posto de trabalho, enquanto que esse valor foi de $48,2 \%$, entre os concluintes.

Pode-se perceber, também, que os estudantes concluintes e iniciantes diferem na preferência de horário de trabalho: enquanto os primeiros preferem horário mais flexível, os últimos preferem horário fixo. Os concluintes dão mais valor à carreira do que os iniciantes: a maioria daqueles disse que o tempo ideal para permanecer em uma única empresa seria enquanto o cargo estivesse acrescentando algo a carreira.

Parte dos concluintes se mostrou desiludida com a preparação que o curso proporciona: uma parcela significativa, $24,7 \%$, disse que ficaria pouco preparada após a graduação. Porém, tal fato não impactará negativamente no padrão de vida, pois tanto nesse grupo, quanto no grupo dos iniciantes há grandes expectativas de melhora no padrão de vida quando comparado ao dos pais.

Ambos os grupos, iniciantes e concluintes, esperam, quando formados, obter reconhecimento profissional. Considera-se que este seja um dos grandes desafios para os graduandos. Mais do que apenas se inserirem no mercado de trabalho, os alunos esperam ocupar uma posição em que possam participar de decisões, desempenhando atividades de complexidade intelectual, condizentes com a formação obtida. Ocorre que, em função do desequilíbrio entre número de alunos formados em Administração (em face da enorme oferta de cursos na área) e oportunidades no mercado de trabalho, é bastante frequente encontrar administradores trabalhando em ocupações executoras e não como executivos. Destaque-se ainda o fato de o acesso a cargos gerenciais no Brasil ser fortemente influenciado por elementos não meritórios, como origem social, capital social e cultural, cor da pele e sexo. Helal, Neves e Fernandes (2007) mostram a existência de uma clara barreira na hierarquia ocupacional no país: o acesso a cargos gerenciais, por exemplo, é destinado fortemente a homens, brancos, residentes no sul e sudeste do país.

Novos estudos sobre o assunto poderiam indicar como tem ocorrido a inserção dos jovens administradores no mercado de trabalho, bem como explorar e explicar as barreiras de acesso a cargos mais destacados como os gerenciais. Parece oportuno que sejam realizados estudos qualitativos, baseados na história de vida, com vistas a aprofundar questões subjetivas que estejam ligadas a inserção destes jovens na vida profissional. A partir de tais perspectivas, questões como escolhas e trajetórias profissionais, bem como a influência de variáveis sociais e familiares neste processo, poderiam ser analisadas e esclarecidas.

\section{Referências}

BARROS, Alexandre R. 0 setor informal e o desemprego na região metropolitana do Recife. REN - Revista Econômica no Nordeste, Fortaleza, v.28, n.especial, p.337-361, jul.1997.

BERTERO, Carlos Osmar. Ensino e Pesquisa em Administração. São Paulo: Thomson 
Learning, 2006.

BOURDIEU, Pierre. Le capital social - notes provisoires. Actes de la Recherche en Sciences Sociales, Paris, n.31, jan. 1980, p.2-3.

BOURDIEU, Pierre. Reprodução cultural e reprodução social. In: S. Miceli (org.). A Economia das Trocas Simbólicas. 2.ed. São Paulo: Ed. Perspectiva, 1987.

BRASIL. MEC/INEP. Resumo Técnico: Censo da Educação Superior 2008. Brasília: MEC/INEP, 2009.

CASTELLS, Manuel; PORTES, Alejandro. World Underneath: the origins, dynamics, and effects of the informal economy. In: A. Portes; M. Castells e L. Benton (eds.). The Informal Economy. Baltimore: The Johns Hopkins University Press, 1989.

CAVALCANTI, Clóvis. Viabilidade do Setor Informal: a demanda de pequenos serviços no Grande Recife. 2.ed. Recife: Editora Massangana, 1983.

FERNANDES, Danielle Cireno; HELAL, Diogo Henrique. Ação afirmativa na educação. In: OLIVEIRA, D.; DUARTE, A.; VIEIRA, L. (orgs.). Dicionário de Trabalho, Profissão e Condição Docente. Belo Horizonte: Ed. UFMG, 2010.

GARVIN, David A. Managing quality: the strategic and competitive edge. EUA, Nova York: Harvard Business School, 1987.

GRANOVETTER, Mark. The strength of weak ties. American Journal of Sociology, v. 78, n.06, p.1360-1380, may, 1973.

GRANOVETTER, Mark. Getting a Job: a study of contacts and careers. 2.ed. Chicago: The University of Chicago Press, 1995.

GUIA DO ESTUDANTE. Melhores Universidades. 2010. São Paulo: Editora Abril, 2010.

HELAL, Diogo Henrique; NEVES, Jorge Alexandre Barbosa; FERNANDES, Danielle Cireno. Empregabilidade gerencial no Brasil. Rev. Adm. Contemp. Eletrônica 2007, vol.1, n.2, pp. 119. Maio/Ago. 2007.

HELAL, Diogo Henrique; ROCHA, Maíra. O discurso da empregabilidade: o que pensam a academia e o mundo empresarial. Cad. EBAPE.BR, Mar 2011, vol.9, no.1, p.139-154.

MACIEL, Cristiano de Oliveira; HOCAYEN-DA-SILVA, Antonio João; CASTRO, Marcos de. 0 ideário de escola na ótica dos docentes: pura subjetividade ou padrões estruturados de cognição nos Cursos de Administração?. Rev. Adm. Contemp. 2008, vol.12, n.3, pp. 659-688.

MAINARDES, E.; DOMINGUES, M. Qualidade de cursos de Administração e Instituições de Ensino Superior em Joinville - SC: um estudo sobre fatores relacionados ao mercado de trabalho na percepção dos alunos. R. Bras. Neg., São Paulo, v. 12, n.35, p. 208-223, abr/jun. 2010.

MATTOS, Pedro Lincoln C. L. Administração é ciência ou arte? 0 que podemos aprender com esse mal-entendido. Revista de Administração de Empresas, Rio de Janeiro v. 49, n.3 p. 349-360, julho/set., 2009.

MOTTA, F. C. P. A questão da formação do administrador. Revista de Administração de Empresas, Rio de Janeiro, v. 23, n.04, p. 53-55, out./dez. 1983. 
NEVES, José Luis. Pesquisa Qualitativa - Características, Usos E Possibilidades, Cadernos de Pesquisa em Administração, São Paulo, v.1, nํ3, 2º̛sem./1996

OLIVEIRA, F. B. A contribuição estratégica da educação. In: OLIVEIRA, F. B. (Org.). Tecnologia da informação e da comunicação: desafios e propostas estratégicas para o desenvolvimento dos negócios. São Paulo: Pearson Prentice Hall, 2006.

OLIVEIRA, F. B.; SAUERBRONN, Fernanda. F. Trajetória, desafios e tendências no ensino superior de administração e administração pública no Brasil: uma breve contribuição. Revista de Administração Pública, v.41 no.spe, p. 149-170, 2007.

PAES DE PAULA, Ana Paula; RODRIGUES, Marco. Pedagogia crítica no ensino de Administração: desafios e possibilidades. RAE - Revista de Administração de Empresas, ed. Especial Minas Gerais,v.46, 2006.

PARKER, M.; JARY, D. The McUniversity: organizations, management, and academic subjectivity. Organazition. v.2, n.2, p. 319-338, 1995.

PFEFFER, J.; FONG, C. T. The end of business schools? Less success than meets the eye. Academy of Management Learning \& Education, v. 1, n. 1, p. 78-95, 2002.

PIORE, M.; SABEL, C. The second industrial divide. New York: Basic Books, 1984.

POCHMAN, M. 0 emprego na globalização. a nova divisão internacional do trabalho e os caminhos que o Brasil escolheu. São Paulo: Boitempo, 2001.

SCHULTZ, Theodore W. Investment in human capital. American Economic Review, v.51, p.01-17, Mar. 1961.

SOARES, J.; RIBEIRO, L.; CASTRO, C. Valor Agregado de Instituições de Ensino Superior em Minas Gerais para os Cursos de Direito, Administração e Engenharia Civil. Dados, Rio de Janeiro, v.44, n.2, 2001. 